\title{
Los comienzos de la hospitalidad santiaguista: el Hospital de Ávila
}

\author{
ÁnGela MADRID Y MEDINA \\ Instituto de Estudios Manchegos (CECEL)
}

\begin{abstract}
RESUMEN ABSTRAT
El presente trabajo trata de la hospitalidad de las Órdenes Militares, en especial de la de Santiago, y de su temprano hospital de

Ávila.

The content of this work is the hospitality of the Militaries Orders, especially the Order of Santiago and her premature hospital of Avila.
\end{abstract}

\section{PALABRAS CLAVE}

Orden de Santiago, hsopitalidad, Ávila.
KEY WORD

Order of Santiago, hospitality, Ávila.

\section{INTRODUCCIÓN}

El hospital de la Orden de Santiago de Ávila no es un hospital de grandes proporciones ni de mucha proyección, posiblemente por el alejamiento de la frontera. Quizá por esas características tampoco cuenta con una documentación abundante. Al contrario, resulta insuficiente.

Sin embargo, tiene el interés de ser de los hospitales más antiguos de la Orden y de haber tenido sus orígenes con la antigua hermandad de Ávila, pasando después a Santiago.

\section{ORIGENES}

El profesor José Luis Martín ha sido, junto con Lomax ${ }^{1}$, uno de los grandes estudiosos de los orígenes de la Orden de Santiago ${ }^{2}$. Sin discrepancias hasta el mo-

\footnotetext{
Derek W. Lomax. La Orden de Santiago (1170-1272). Madrid, 1965.
} 
mento sobre el tema, siendo así que ambos dan como precedente de la Orden la hermandad de los Fratres de Ávila.

Sin abundar en ello, quizá convenga recordar brevemente que Rades y Andrada cuando escribió en el siglo xvi su Crónica de Santiago ${ }^{3}$, apuntaba la posibilidad, basándose en el prólogo de la Regla ${ }^{4}$ de la Orden, de que hubiera existido con anterioridad a la fundación una hermandad o cofradía de Santiago nacida a raíz de la victoria de los cristianos en Albelda (859), cerca de Clavijo.

La existencia de esa primitiva hermandad podria explicar, en opinión de Rades, un privilegio del convento femenino de Sancti Spiritus de Salamanca, según el cual el convento nace a partir de una donación de Fernando I, cuando decidió dar al mismo la tierra y las rentas de la encomienda del primer caballero de Santiago muerto en batalla.

En cualquier caso, la fecha generalmente admitida para la fundación de la Orden de Santiago es el 1 de agosto de 1170, momento en el que un grupo de caballeros encabezados por Pedro Fernández y constituidos en confraternidad o hermandad religioso-militar, reciben del rey de León Fernando II la plaza de Cáceres para su defensa.

De ahí que se considere fundador de la Orden al maestre Pedro Fernández y que el primer nombre adoptado por la hermandad fuese el de Fratres de Cáceres. Originariamente la Orden se podría encuadrar entre esas hermandades surgidas en las ciudades en el siglo XII, con carácter piadoso, para prestar servicios sociales o entre las propias milicias concejiles.

Este fenómeno asociativo generalizado de la Edad Media, al que no es ajena la solidaridad, ya fue objeto de estudio en un encuentro en el que participó también José Luis Martín ${ }^{5}$.

El segundo precedente importante lo constituyó otra hermandad, la de los Fratres de Ávila, milicia de carácter religioso que terminó siendo absorbida por la Orden de Santiago y con ella su hospital.

Precisamente la primera noticia documental sobre las bases para un hospital santiaguista la tenemos en la donación de la villa de Bolobres en 1172 por Alfonso VIII a los fratres de Ávila ${ }^{6}$. Aunque José Luis Martín ${ }^{7}$, siguiendo a Julio González,

Jose Luis MARtin. Origenes de la Orden Militar de Santiago (1170-1195). Barcelona, 1974.

Edición facsimil. Barcelona, 1980.

${ }^{4}$ Regla y Establecimientos de la Caballeria de Santiago del Espada. Valladolid, 1991

${ }_{5}$ Cofradias, gremios, solidaridades en la Europa Medieval. XIX Semana de Estudios Medievales. Estella, 1993, pp. 127-147

${ }^{6}$ Ego Adefonsus, Dei gratia Yspaniarum rex, dono et concedo Deo et uobis fratres de Auila, pro animabus aui et patris mee nec non et parentum meorum et pro salute etiam anime mee, unam uillam quod uocatur Bolobres et est in rippa de Tago, cum terris, uineis, cum molendinus et piscariis, pratis et pascuis cultis et incultis, cum ingressibus et egressibus et cum omnibus terminis et pertenenciis suis, ubicumque fuerint. Ut habeatis et possideatis iure hereditario in perpetuum, excepto ius eclesie. AHN. OO.MM. Uclés. Cajón $56, n .{ }^{\circ} 1$

La Crónica de Santiago menciona el hospital en el folio $18 \mathrm{v}$.

7 Martín, p. 209. 
considerando que la fecha que figura en el documento no está de acuerdo con los confirmantes y el texto, la rebaja a 1168-1170.

Si estamos hablando de precedentes no puede sorprendernos lo temprano de la fecha. Por la antigüedad de los datos con que contamos le seguiría el hospital de Cuenca, cuyas bases las pone Alfonso VIII en 1177 cuando entrega a la Orden, en agradecimiento por la ayuda prestada en la conquista de la ciudad, unas casas junto al alcázar ${ }^{8}$.

Del hospital de Las Tiendas tenemos noticias de 1180 , cuando el mismo monarca concedió fuero a dos lugares próximos a Saldaña, Villasilla y Villamelendro, que formaron parte del patrimonio del hospital ${ }^{9}$. Dos años más tarde Téllez de Meneses y Pedro Fernández entregaron al mismo la mayoría de las posesiones que Alfonso VIII les había otorgado por la participación en la conquista de Cuenca ${ }^{10}$.

José Luis Martín también nos informa de la confirmación hecha en 1186 por Fernando II y su hijo sobre la donación de unas tierras en León realizada por la infanta Urraca al hospital ${ }^{11}$.

En 1187 el papa Urbano VIII pide que unas limosnas sean destinadas al hospital de cautivos de Toledo ${ }^{12}$. El de Teruel pudo ser fundado en 1188 por Alfonso II ${ }^{13}$. Inmersa en la encomienda de Cámara de los Privilegios y en la subencomienda de Uclés existía en 1191 la encomienda de la enfermería, destinada a atender a los caballeros ${ }^{14}$. Pedro Fernández de Castro da a esta enfermeria en 1191 sus pertenencias en Peñafora y en 1198 una viña en Guadalajara ${ }^{15}$.

\section{LA HOSPITALIDAD EN LAS ÓRDENES MILITARES}

El tema asistencial es uno de los que menos interés han venido suscitando en la historiografía española de las órdenes militares. En general se le ha infravalorado, considerándolo secundario con respecto a otras actividades. $Y$, desde luego, a las militares. Incluso en la Orden de San Juan de Jerusalén, orden hospitalaria por excelencia, han sido estudiadas encomiendas, rentas, patrimonio artístico, más que la dimensión humanitaria. Menos aún en el caso de las órdenes españolas. Fenómeno que seguramente también pueda explicarse por el hecho de que la documentación sobre hospitales es más escasa, al menos en el periodo medieval.

- Ángela MAdRID MEDiNA. "La hospitalidad en las Órdenes Militares españolas", en Lux Hispariarum. Madrid, 1999, pp. 249.

Ibidem, p. 250.

10 Ibidem, p. 254.

1 Martin, p. 379-80. Madrid , p. 246.

12 Ibidem, p. 252.

13 Ibidem, p. 246.

14 Ibidem.

15 Ibidem. p. 254. 
Por otro lado quizá se ha simplificado la vinculación y, podemos admitirlo, relación causa efecto de las órdenes militares con respecto al fenómeno de las cruzadas. En su doble vertiente: las que se dirigian a Tierra Santa y la cruzada que representa la reconquista española. No faltan quienes consideran que no existe otra función para las órdenes militares que esa lucha armada o que en ella nace y termina la razón de su existencia. Por eso, concluida ésta, carecen de funcionalidad.

Me parece oportuno, además, recordar que no todas las órdenes nacen como militares ${ }^{16}$ y que, junto a ese aspecto pueden ser objeto de consideración otros, como el religioso, el caballeresco, el colonizador, con lo que de administración conlleva, relaciones institucionales, ordenamiento jurídico. $Y$, desde luego, la hospitalidad. En cualquier caso la función militar no fue la única, ni excluyente.

Las órdenes, convertidas en militia Dei, van a participar de los objetivos y proyectos del pontífice. Pero las propias motivaciones de las cruzadas son fundamentalmente dos. De un lado auxiliar a los hermanos en la fe de Oriente. De otro proteger a los peregrinos de Tierra Santa de los asaltos y asesinatos.

Es verdad que los templarios jugaron un papel defensivo de primera magnitud en Tierra Santa, incluso después de la pérdida de Jerusalén. Pero no conviene olvidar que cuando nace el Temple, hacía 1120, el caballero Hugo de Payns se ofrece con sus compañeros para proteger a los peregrinos y proceder a la defensa armada de la fe. San Bernardo consagra este género de vida en la carta abierta $D e$ laude novae militiae.

Por su parte las órdenes de San Lázaro, Santa María de los Teutones y Santo Tomás de Acre tienen como primera función la asistencial, aunque luego se militaricen. La de San Lázaro, dedicada a su leprosería, tarda un siglo en hacerlo, a mediados del XIII. Hasta entonces, es decir, durante una centuria, el maestre era también un leproso.

El origen de los caballeros teutónicos está vinculado a la fundación de un hospital alemán cerca de Acre. La orden de Santo Tomás desarrolló actividades humanitarias y hospitalarias, asi mismo. Por lo que se refiere a la orden del Santo Sepulcro no se la puede considerar militar propiamente.

En cuanto a la orden de San Juan de Jerusalén su nacimiento, como es bien sabido, está vinculado a la actividad hospitalaria, incluso antes de las cruzadas, a partir de aquellos comerciantes de la ciudad italiana de Amalfi y sus fundaciones. En un principio la Orden no ofrecia protección armada, sino que se dedicaba a hospedar y asistir a peregrinos sanos y enfermos a través de un complejo constituido por un hospital y dos conventos, uno masculino y otro femenino.

16 Gonzalo Martinez Diez. La cruz y la espada. Barcelona, 2002. Carlos de Ayala Martinez. Las ordenes militares hispánicas en la Edad Media. Madrid, 2003. 
Más adelante procedieron a militarizarse y hasta llegaron a actuar, ya en época moderna, de policía de los mares en el Mediterráneo. Pero nunca abandonaron la actividad que le es propia y especifica y que la ha llevado a ser considerada la orden hospitalaria por excelencia, llegando a ser conocida expresamente por ese nombre.

De hecho y precisamente por ello, ante crisis como la que termina con los templarios, cuando ya no desarrollan ese papel militarizado de las cruzadas o la reconquista, los sanjuanistas con una vida discreta, ocupados en sus funciones hospitalarias, se libran de los ataques que terminaron con la poderosa orden del Temple.

Con todo, en la Península Ibérica las órdenes que contaron con un número mayor de hospitales fueron la de Santiago (al menos dieciséis), llegando a constituir algunos importantes complejos, como los antes mencionados de Toledo y de Cuenca, y naturalmente la de San Juan de Jerusalén, de la que son unos cincuenta hospitales de los que tengo noticia hasta el momento ${ }^{17}$. Con una mayor concentración en el Camino de Santiago y en La Mancha. En este caso porque en el Priorato de la Orden debieron agruparse también un mayor número de caballeros.

Pero cuando hablamos de temas asistenciales no podemos perder de vista un aspecto, decisivo a mi modo de ver, y es que los freires que más dedicación prestan a esta función no tienen filiación cistercienses. De hecho, las órdenes militares con mayor desarrollo en sus actividades humanitarias siguen la regla de San Agustín, la tercera de las órdenes mendicantes, junto a franciscanos y dominicos.

Es la regla de los hospitalarios. Una versión adaptada de ella sigue la Orden de San Lázaro y en España también adoptan esa regla la Orden de Santiago y la efímera Orden de San Jorge de Alfama, luego incorporada a la de Montesa.

Si en la documentación orgánica de las órdenes militares aparecen, desde luego, las obligaciones de solidaridad y hospitalidad, en la Orden de San Juan es parte fundamental de la misma. Desde la bula fundacional Piae Postulatio voluntatis de 1113 del papa Pascual II, en que ya se menciona la atención a pobres y peregrinos.

La normativa hospitalaria, en general, se agrupa en atención a los pobres y atención a los propios freires. En el primero de los casos abundan las disposiciones referentes a aspectos sanitarios y otras dirigidas a los administrativos y económicos.

La documentación del Archivo Histórico Nacional guarda algunos de estos estatutos y establecimientos. Especial interés tiene el códice navarro de 1314, al

17 Sobre hospitales de la Orden y su distribución puede verse Adrián ARCAz POzO «La hospitalidad Sanjuanista en la Galicia Medieval", en I/ Jornadas de la Orden de San Juan. Ciudad Real, 1999, pp. 5364. Ángela MADRID MEDINA "La Orden de San Juan de Jerusalén en La Mancha. Su proyecto hospitalario". Ibidem, pp. 37-52 
que ya me referí en las Jornadas de la Orden de Arenas de San Juan, y hoy afortunadamente publicado por Ricardo Cierbide Martinena ${ }^{18}$.

La vocación hospitalaria de la Orden de San Juan en la Península se va a manifestar con dos características fundamentales. De un lado el deseo de mantener el mayor número posible de hospitales, a diferencia de lo ocurre con la Orden de Santiago, que con el paso del tiempo tiende a la concentración. De otro la permanencia en el tiempo.

Con respecto al territorio castellano-manchego destaca la abundancia de hospitales. Que se puede explicar por tratarse de un territorio muy compacto de órdenes militares, por encontrase en la frontera con los musulmanes, caso de las órdenes hispánicas, y por el relanzamiento efectuado por los sanjuanistas. Así como la permanencia en el tiempo. Posiblemente porque los hospitales de órdenes no son suplidos por otros de los concejos.

Las órdenes de caballería hispánicas de Santiago, Calatrava, Alcántara y Montesa contaron todas con una actividad hospitalaria, más desarrollada en la de Santiago, porque es la orden que gozó de mayor extensión y de más poder y porque es la que se asemeja más a la Orden del Hospital. Sus instalaciones hospitalarias se reparten por la frontera y por el Camino de Santiago. Alguna de las cuales, caso de Cuenca, ha mantenido su actividad desde finales del siglo XII hasta nuestros días.

Los santiaguistas estaban obligados, por ejemplo, a entregar las ganancias del botín obtenido en sus enfrentamientos con los musulmanes para el rescate de cautivos, una de las principales actividades asistenciales que desarrollaron.

En la Orden de Santiago la bula fundacional del papa Alejandro III al confirmar la Orden en 1175 alude a la especial atención que hay que dispensar a los huéspedes y a los pobres. Lo que queda recogido en el capítulo III de la Regla ${ }^{19}$, bajo el título de Como han de recibir y dar las cosas necessarias a los pobres de lesu Christo. Con un desarrollo normativo. En lo que se insiste en la documentación orgánica e institucional de la Orden.

No sólo regulan las obligaciones humanitarias los santiaguistas. Los calatravos recogen algunas en sus Definiciones ${ }^{20}$. Y en documentación diversa los montesianos $^{21}$. Con todo lo cual las órdenes militares hispánicas sintieron también esa vocación y fundaron una serie de hospitales. La evolución de las instituciones hospitalarias está estrechamente relacionada con la distribución y dedicación de las mismas.

\footnotetext{
Pamplona, 1999

Op. cit.

Diffiniciones de la Orden de Calatrava. Edición facsimil. Ciudad Real, 2003.

21 De ello me ocupo en "Dimensiones de las órdenes militares. La actividad asistencial», en Cursos de verano de Gandia 2004. En prensa.
} 


\section{EL HOSPITAL DE ÁVILA}

El hospital de Ávila, bajo la advocación de San Mateo, aparece en la documentación vinculado al monasterio del mismo nombre y a una capellanía de dicho convento, extramuros de la ciudad.

La primera noticia del mismo como tal la encontramos en la compra que el comendador del hospital realiza de un prado próximo al monasterio ${ }^{22}$. Es importante, sin embargo, dentro del conjunto, constatar la separación entre el hospital, bajo un comendador y el convento, regido por una comendadora.

Una de ellas, Dominga Ximeno, fundó en él una capellanía perpetua, que fue enriquecida con las donaciones de María Gonzalo y Andierazo Blasco en 1256. Entre las propiedades con que dotaron a la capellanía aparecen casas ${ }^{23}$, de las que acaso el hospital pudo beneficiarse.

Nos hace pensar también en ello la donación realizada en 1298 del quinto de sus bienes a favor del hospital por parte de Domingo Gómez de Pinilla y Blasco Pérez de Cardeñosa, hijo de Estefanía Blasco ${ }^{24}$. Es destacable la vinculación que tiene el comendador del hospital de Toledo, al que el de Ávila terminó por incorporarse ${ }^{25}$, en ese proceso de concentración al que antes nos referiamos.

Con todo, el de Ávila se esfuerza por mantener sus privilegios. Alfonso XI confirma otros anteriores de Fernando IV y Sancho IV, referentes a exención tributaria de los freires, freiras y paniaguados del monasterio (en Burgos el 25 de noviembre de 1324), y del papa (en Ciudad Rodrigo, 22 de marzo de 1338), en lo que se refiere al respeto debido a los derechos de la Orden y a sus propiedades ${ }^{26}$.

2. In Dei nomine. El acomendador (sic) Sancho Asensio comparó (sic) el prato de Petro Diego [e de] don Gal, filio de Gali Pugeso e de Gómez Blasco... el prato que iacet inter los pratos del mon[asterio] de Sant Mateus e isto parto por al mesón e de isto prato fiadores e uendedores todos tres...e sunt [pagados] de sex maravedis. AHN. OO. MM. Uclés. Carp. 56, n. 3. El documento, sin fecha, podría ser de mediados del siglo Xi!.

$2.3 \mathrm{lbidem}, \mathrm{n}^{\circ} 2$.

24 In Dei nomine. Sepan quantos esta carta vieren como Domingo Gomes [de Pinilla] e yo Blasco Pérez de Cardeñosa, fijo de Estefania Blasco de Branos, otorgamos e conscemos que fazemos tal pleyto e tal postura con [Vasco de] Yagüe, comendador del ospital de Sant Matheos de Auila e deudor de los algos que la Orden de Sanyagüe ha en el ospital de la dicha Orden por el maestre e por el comendador del ospital de Toledo, porque el dicho maestre e el comendador de Toledo touieron por bien que nos. Diego Gomes e Blasco Pérez, los dichos, fuesemos [freyles] e conpañeros con los freyles que [... ] este primero que viene todo el quinto del mueble de todo mi algo. E que nos demos e nos entreguemos de todo el quinto e toda mi rayz. E que lo tengamos nos Diego Gomes e Blasco Pérez por toda nuestra vida. E después que nos muriéramos que finque todo el nuestro quinto de la rayz libre e quito de la dicha Orden. N. 4.

${ }_{25}^{25}$ Asi aparece en el siglo XVI. MADRio. Lux..., p. 260.

26 Sepan quantos esta carta vieren como yo don Alfonso, por la gracia de Dios rey de Castilla, de Toledo, de León. de Gallizia, de Seuilla. de Córdoua, de Murçia. de lahen. del Algarbe e señor de Molina, vi una carta del rey don Fernando, mio padre, que Dios perdone, fecha en esta guisa: Sepan quantos esta carta vieren como yo don Fernando por la gracia de Dios rey de... vi una carta de cuero fecha en esta guisa: Sepan quantos esta carta vieren como yo don Fernando... vi una carta del rey don Sancho. mio padre, que Dios perdone, que él ouo dado a la Orden de Huclés fecha en esta guisa: Don Sancho pcr la gracia de Dios rey de Castilla, de Toledo, de León, de Gallisia, de Sevilla, de Córdoua, de Murçia, de la- 
El último documento de la carpeta del hospital que nos ocupa es ya de 1515. Se refiere a una visita de la Orden de Santiago a la capellanía del convento de San Mateo, que se hallaba extramuros de la ciudad de Ávila. Entre sus posesiones aparecen tierras, viñas, prados y casas $^{27}$.

A diferencia de otros hospitales santiaguistas ignoramos a quienes atendia el de Ávila. Quizá quedaba ya un poco alejado de la frontera para ser un hospital de sangre. Por otro lado, considerando la importancia que la Orden concedía a la redención de cautivos, actividad que desarrollaron otros en los primeros tiempos, cabría pensar que fue ésta la dedicación del hospital de San Mateo.

No es frecuente que estos hospitales tengan relevancia para el patrimonio artístico. Los edificios tenían carácter funcional. Se trataba de casas rurales de reducidas proporciones, sencillas, y estructura compacta. Solían contar con un patio trasero para esparcimiento de los internos y un corral.

Los acogidos a ellos estaban separados por sexo o se distribuian en hospitales distintos. Los femeninos se ponían bajo la advocación de la Virgen, mientras que los masculinos estaban dedicados al patrón de la Orden o a santos conocidos por su ejercicio de la caridad.

El aspecto religioso se recoge en la presencia, según los casos, de capillas o simplemente de altares. A veces tienen adosadas a su estructura ermitas. En el caso de Ávila es el hospital el que estuvo vinculado al complejo del monasterio.

Finalmente, como hemos dicho, quedó incorporado al hospital de Toledo, que habia pasado de la antigua dedicación a casa de pobres. Con la crisis del último tercio del siglo $\mathrm{xV}$, a la que la Orden de Santiago no fue ajena, la actividad de este hospital habia quedado reducida a una hospedería en una casa cercana ${ }^{28}$.

Sin embargo, la situación no tardó en cambiar. Los antiguos hospitales medievales los hemos visto concentrarse a favor de algunos como los de Toledo y Cuenca para los que en el siglo XVI se realizaron edificios importantes, con una renovación, incluso de criterios sanitarios, tales como la incorporación de letrinas y el incremento de vanos con balcones que mejoraban la ventilación y permitían que se distrajesen los enfermos.

Para Toledo en el Capítulo General de la Orden de 1500 se decide una renovación total. Tanto en la función (destinándose ahora a los enfermos de bubas),

hen, del Algarbe, a qualesquier cogedores o cualquier cogedor que sea en Auila de los mios pechos salut e gracia. Sepades que don Pedro Ferrandes, maestre de la cauallería de Sanctiago, me enbió dezir que demandáuandes pechos a los sus freires e a las freiras e a los paniaguados del su monasterio de Sant Matheos den de Áuila, que les pendrades e les fasedes mucho mal por esta rasón e los pasades contra sus priuillegios e contra las cartas que tienen del rey mio padre e mias. $E$ esto non tengo yo por bien que los freires nin las freiras nin los sus apaniaguados (sic) que pechen, que es cosa que nunca fue. AHN. OO.MM. Uclés. Carp. $56, n .^{\circ} 5$ y n. ${ }^{\circ} 6$. El texto se repite en el $n .^{\circ} 7$.

27 Ibidem, n. ${ }^{\circ} \mathrm{Y}$

28 Inés Melero Fernandez . "Descripción del hospital de Santiago de Toledo a fines del siglo xv", en Anuario de Estudios Medievales. 1981, pp. 459-463. 
como por la construcción de un nuevo edificio con las rentas del hospital y de derechos de Toledo, Badajoz, Ciudad Real y Ávila.

En la nueva fábrica conservaron la iglesia, con capillas de enterramiento, y el claustro, en los que permanecieron los estilos gótico y mudéjar. El hospital siguió las formas renacentistas, con plata centralizada. Contaba con dependencias médicas, residenciales y económicas (horno, pajar..), constituyendo un complejo importante. En los testeros de cada enfermería habia altares ${ }^{29}$.

El hospital de Santiago de Cuenca fue el otro hospital de la Orden en el que se realizaron obras de envergadura hasta convertirse en un importante edificio, que mantiene el esquema medieval, con elementos mudéjares y renacentistas. Es el que ha mantenido su actividad ininterrumpidamente hasta nuestros días.

En cualquier caso, el mucho más modesto hospital de Ávila cumplió su función en los orígenes de la hospitalidad santiaguista y contribuyó al engrandecimiento del hospital de Toledo.

29 Olga Pérez monzón. «El hospital de Santiago de Toledo en el siglo XVI», en IX Congreso Nacional de Historia del Arte I. León, 1994, pp. 355-356. 